УДК 622.1

\title{
ИССЛЕДОВАНИЕ ОБРУШЕНИЙ ГРУНТА НАД НЕГЛУБОКОЙ ЗАБРОШЕННОЙ ШАХТОЙ ДЛЯ ОПРЕДЕЛЕНИЯ ГЕОТЕХНИЧЕСКИХ УСЛОВИЙ ИНДИВИДУАЛЬНОГО СТРОИТЕЛЬСТВА
}

\author{
Усанов Сергей Валерьевич', \\ usv@igduran.ru
}

\author{
Усанова Анна Витальевна 1 , \\ anne.usanova@gmail.com \\ 1 Институт горного дела Уральского отделения Российской академии наук,
Россия, 620075, г. Екатеринбург, ул. Мамина-Сибиряка, 58.
}

Актуальность исследования обусловлена необходимостью строительства зданий и сооружений над старыми заброшенными шахтами. Строительство связано с опасностью провала земной поверхности и разрушения зданий. Эта проблема имеет широкое распространение во всем мире.

Цель: определить риск застройки небольшого участка земли, который расположен над старой золоторудной шахтой, определить параметры вероятных опасных процессов и спрогнозировать потенциальный ущерб.

Методы: анализ архивных горно-геологических документов заброшенной шахты, реконструкция и двумерное моделирование горных выработок под исследуемой территорией, натурное визуальное обследование поверхности, анализ архивных оптических космических снимков, анализ базы данных обрушений поверхности, геофизические зондирования горного массива с дневной поверхности.

Результаты. С помощью двумерного моделирования установлено, что из двух гранитоидных даек, которые разрабатывались в границах исследования, только одна представляет опасность, так как другая по геологическим условиям основным телом залегает за пределами исследования. Это облегчает условия для строительства. Опасные процессы от штрека и орта дайки, которая падает по участок, могут быть только в самой западной части шириной 5 м. Установлено, что с 1957 г в этом месте не наблюдалось провалов поверхности, а опасные явления, зарегистрированные в окрестностях, представляют из себя проседание грунта диаметром 1-2 м и глубиной 0,5 м. В юго-западном углу участка над ортом георадаром выявлена зона глубиной 3 м, заполненная крупно- и мелкообломочным материалом, что, вероятнее всего, является следствием от его обрушения. Индикаторы, которые могут быть идентифицированы как пустоты или дезинтегрированный массив, не обнаружены двумя методами.

Выводы. Сделан прогноз параметров вредного влияния старой шахты на устойчивость поверхности. Исследованиями установлено, что на этом участке над заброшенной шахтой можно построить коттедж без риска необратимых повреждений во время эксплуатации. Земля безопасна для строительства и проживания. Определены геометрические параметры и частота проявлений вредного влияния подземной разработки. Предложены геотехнические меры минимизации возможного вредного влияния заброшенной шахты.

\section{Ключевые слова:}

Заброшенная шахта, старые выработки, обрушение грунта, просадки, строительство, безопасность, прогноз и оценка, геотехнические меры, условия размещения здания.

\section{Введение}

Проблема безопасности зданий над старыми шахтами распространена во всем мире. Например, в Австралии насчитывается более 50000 заброшенных шахт (по состоянию на 2012 г.), в Канаде более 10000 (по состоянию на 2000 г.), а в Южной Африке почти 6000 (по состоянию на 2009 г.) [1, 2]. В центральной Европе в 2005 г. насчитывалось 226 горнодобывающих регионов, в 46 \% которых добыча полезных ископаемых полностью прекратилась, т. е. имеют место территории ликвидированных шахт [3]. На территории Великобритании более двух миллионов зданий подвержены воздействию неглубоких угольных шахт [4]. Широко распространены небольшие заброшенные шахты в Конго [5].

Урал более трех веков является рудным и металлургическим регионом России. Исторически так сложилось, что старые и заброшенные шахты находятся в границах многих современных уральских городов (рис. 1). Шахты построены при разработке месторождений черных и цветных металлов, золота, соли и угля [6-10]. При этом использовались разные технологии горных работ, связанные с историческим периодом разработки (XVII-XX в.) и геологическими особенностями. В результате этого опасные процессы на территориях старых шахт протекают с разными параметрами.

Специфика определения качества использования подработанных территорий заключается еще и в том, что с течением времени скудеет информация о геометрических параметрах подземных выработок, о расположении относительно поверхности и способе их погашения. При этом постоянные медленнотекущие природные процессы, такие как изменение гидрогеологических условий [11-13], суффозия [14, 15], выветривание горных пород [16], геодинамические колебания $[17,18]$ и другие изменяют устойчивость поверхности над выработками. В старых зонах обрушения происходит уплотнение грунтов в провале и опасность оседания поверхности снижается, в других местах наоборот - образуются новые провалы.

Многообразие факторов, влияющих на деформирование поверхности старых шахт, обусловило отсутствие унифицированного метода прогноза безопасно- 
сти зданий при застройке таких территорий, несмотря на многообразие регламентирующих документов: СП 21.13330.2012, СП 116.13330.2011, СНиП 22-02-2003, СП 248.1325800.2016 и др. Поэтому безопасность застройки земель над старыми шахтами оценивается на основе комплекса разносторонних исследований. Кроме этого, в России не существует общенациональных программ по реабилитации подработанных территорий. Поэтому на каждом выработанном месторождении, где расположены заброшенные шахты, проблемы решаются с привлечением средств собственников земель, застройщиков или муниципалитетов. Одному из таких примеров посвящена эта статья.

На небольшой площади 15 Ар в районе заброшенной шахты необходимо разместить коттедж. Участок расположен на поверхности Березовского золоторудного месторождения, разработка которого ведется подземными работами с 1748 г. [19]. Форма и распо- ложение земельного участка таковы, что предпочтительное место размещения дома находится в зоне влияния разработки двух даек. Гранитоидные дайки, которые разрабатывались шахтой, в этом месте пересекаются и выходят на поверхность. Горные работы закончились здесь в 1860 г. Данные об обрушениях поверхности, способе и полноте погашения горных выработок отсутствуют. С учетом давности - 170 лет после окончания разработок - вероятность того, что опасные процессы не активизируются при строительстве и эксплуатация коттеджа будет безопасной, высока, но риск повреждения здания остается навсегда $[20,21]$. Запасов золота, подлежащих отработке, под участком нет. Это создает положительную перспективу для строительства. Цель работы - спрогнозировать параметры вредного влияния старых подземных горных работ на земельном участке и выбрать безопасное место для размещения коттеджа.

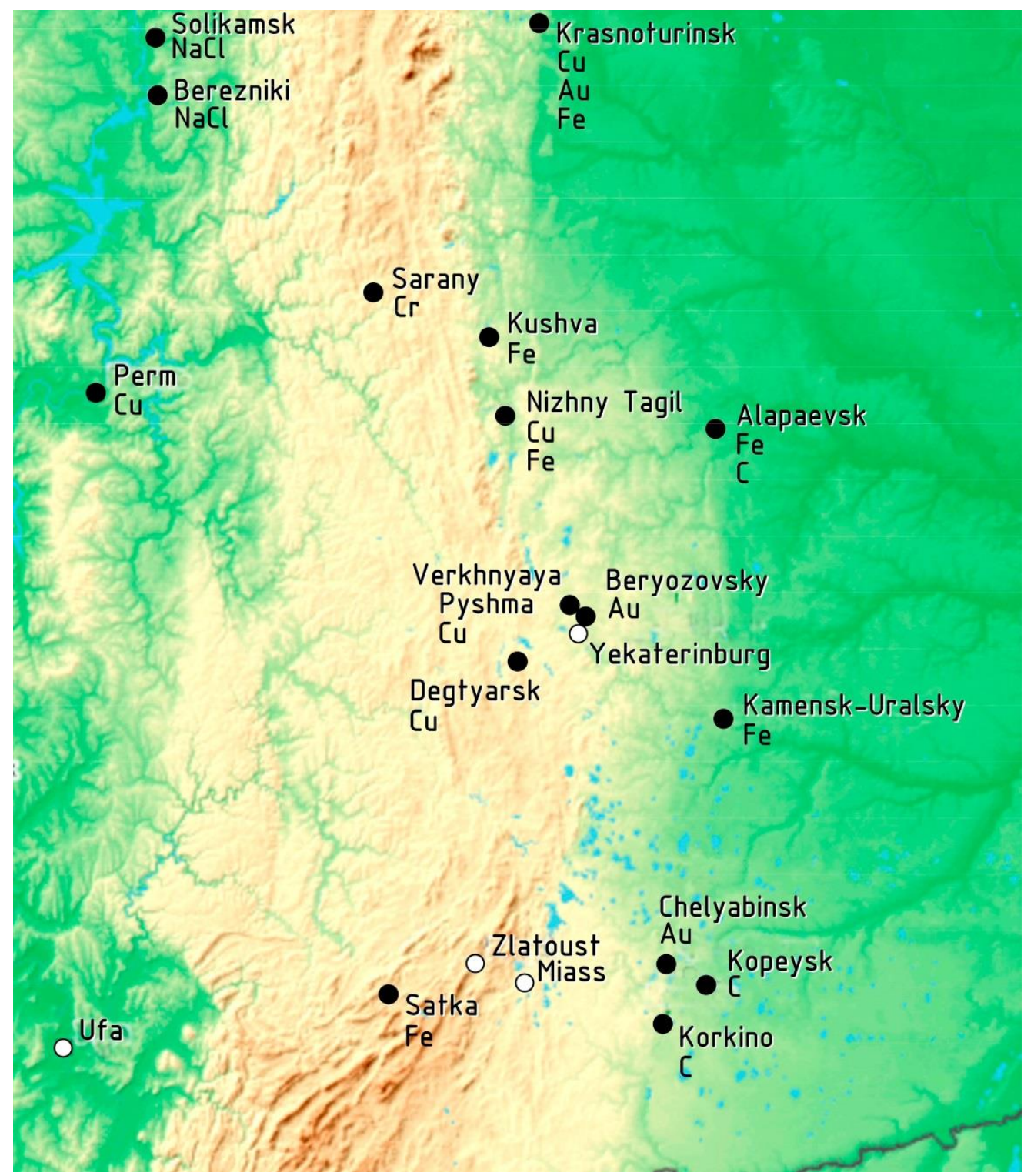

Pис. 1. Города Пермского края, Свердловской и Челябинской областей России, где расположены заброшенные и старые шахты (в качестве базы для создания рисунка использованы данные с сайта [22].

Fig. 1. Cities of Perm Krai, Sverdlovsk and Chelyabinsk regions of Russia, where abandoned and old mines are located (the data from the website [22] is used as the basis for drawing 
Для того чтобы повысить безопасность застройки и проживания в этом месте надо определить:

- места, где может быть проседание грунта в течение всего срока службы конструкции;

- параметры вероятных опасных процессов;

- потенциальный ущерб;

- геотехнические мероприятия для снижения риска.

\section{Методы и материалы}

На исследуемом участке никогда не было инструментального контроля влияния старых горных выработок на деформирование земной поверхности. Доступ в подземные выработки отсутствует. Они ликвидированы, но способ ликвидации и качество погаше- ния выработанных пространств неизвестны. Это обуславливает необходимость комплексного исследования состояния массива горных пород.

На первом этапе исследований выполнен поиск архивной документации о геологических условиях и горных работах, которые здесь велись. В компании, которая продолжает разрабатывать месторождение, обнаружены материалы о расположении рудных тел, их количестве, горизонтальной мощности, направлении падения и угле залегания (рис. 2). Участок расположен в районе даек Спасская и Кривая. Выходы на поверхность даек залегают на западной границе, которая является приоритетной для размещения сооружений, исходя из пожеланий застройщика.



Рис. 2. Расположение земельного участка относительно золоторудных даек и зоны влияния заброшенной шахты

Fig. 2. Location of the land plot relative to the gold dikes and the zone of influence of the abandoned mine

Дайка Кривая имеет пологое западное падение под углом $20^{\circ}$ (рис. 2). Горные работы по данным разработчика месторождения по этой дайке не велись. Если по этой дайке были не задокументированные подзем- ные горные разработки, то с учетом условий ее залегания они должны быть расположены за пределами исследуемой территории. Это еще один положительный фактор в пользу безопасности строительства. 
Дайка Спасская также выходит на поверхность в районе западной границы участка, но имеет крутое восточное падение под углом $70^{\circ}$. Обнаруженная в архивах проекция горных работ на вертикальную плоскость (рис. 3) не имеет координатной привязки к плану поверхности (рис. 2), но оба чертежа выполнены в масштабах. Для их совмещения использованы контрольные точки, которые есть на плане и на проекции - устья ликвидированных вертикальных выработок, расположенные к северу от границ исследова- ния: 1) шахта № 491; 2) шахта вентиляционная. Совместив проекцию горных работ и план поверхности (рис. 3), установлено, что:

- под участком проходит штрек на глубине от поверхности $18 \mathrm{~m}$;

- разработка велась с низкой интенсивностью в период с 1745 по 1860 гг.;

- выработки являются тупиковыми и, скорее всего, носили разведочный характер.

Ceвер

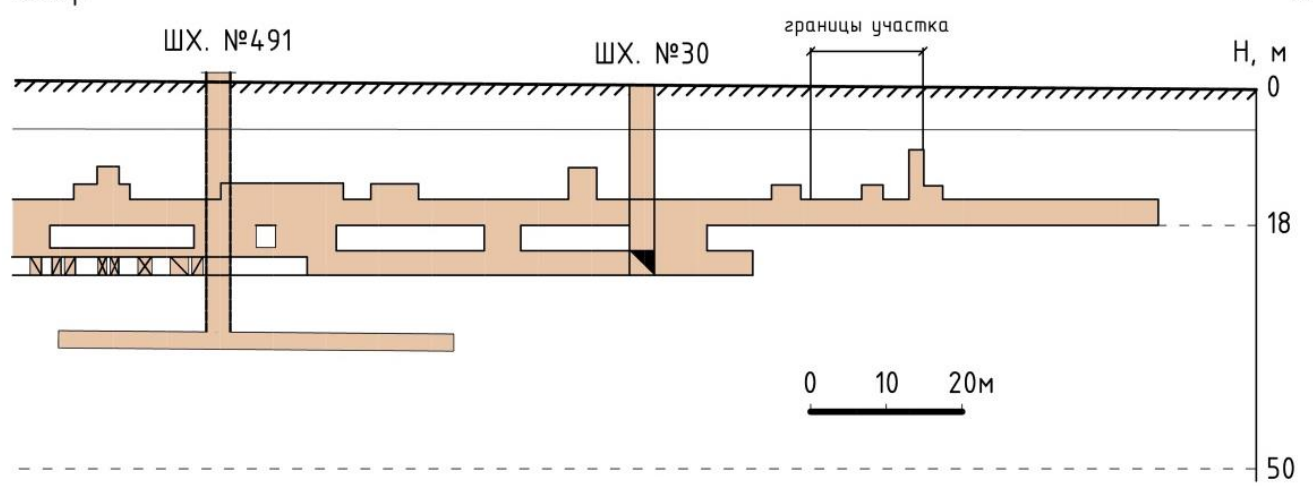

Рис. 3. Фрагмент архивных материалов. Проекция на вертикальную плоскость подземных горных работ вдоль рудного тела Спасская в исследуемом районе

Fig. 3. Fragment of archival materials. Projection on the vertical plane of underground mining operations along the Spasskaya ore body in the study area

Эти данные говорят о слабой нарушенности горного массива. Дополнительно установлена зона вредного влияния горных работ, которая нанесена еще во время разработок и скорректирована позднее с учетом требований нормативного документа по охране зданий и сооружений при разработке Березовского месторождения.

В границах исследования по архивным данным вертикальные горные выработки с выходом на поверхность отсутствуют. Это третий положительный фактор в отношении безопасности строительства. Однако в районе юго-западного угла участка находится слепая вертикальная выработка - восстающий орт высотой 10 м. Если он до сих пор не обрушился, то может представлять опасность для здания.

Для оценки происходивших ранее в этом месте опасных процессов проанализированы журналы регистрации обрушений поверхности. В архивах компании-разработчика месторождения выполнен поиск записей за 1957-2014 гг. Кроме этого, выполнено визуальное обследование поверхности. При натурном обследовании целевыми объектами были следы просадок поверхности, трещины, уступы и другие изменения рельефа. Эти же следы влияния горных работ разыскивались при анализе архивных оптических космических снимков.

Последним этапом был поиск геофизическими методами пустот или разрыхленных горными разработками грунтов. Как правило, в подработанном горном массиве пустоты больших размеров довольно редкое явление. Чаще всего полости от старых шахт находятся в состоянии полного или частичного заполне- ния и отличаются степенью заполнения и плотностью заполнителя.

Основываясь на созданной модели старой шахты, приняты глубина зондирования, шаг зондирования в профиле и сетка профилей с ячейками $3 \times 3$ м, чтобы не пропустить влияния подземных выработок диаметром до 2 м на свойства горных пород. В качестве инструментов использованы метод георадиолокации и спектрального сейсмопрофилирования [23-26]. При исследованиях подземных пустот применяют и другие геофизические методы в зависимости от внешних условий и решаемых задач [27]. Методом георадиолокации зондирование проведено по 14 профилям общей протяженностью 490 м, которые дублируют профили спектрального сейсмопрофилирования. Результаты геофизических исследований сопоставлялись с данными архивных документов и анализировались в комплексе. Это снижает ошибки методов и повышает надежность оценки.

\section{Результать}

На основе архивных данных создана двумерная модель распространения горных выработок под участком (рис. 4). Модель, как результат создания абстрактного представления графических данных для анализа, описания и объяснения условий подработки поверхности горными работами, включает: поверхность, границы индивидуальной застройки, расположение и залегание рудных тел, а также максимальный горизонт горных выработок +18 м. Все данные имеют координатную привязку и выполнены в масштабе. Модель упрощенно воспроизводит залегание даек, так как мало данных 
для точного построения, а геологические данные вообще отсутствуют. Тем не менее из результатов моделирования становится очевидно, что:

- горные работы по дайке Кривая не оказывают опасного влияния;

- подземные выработки по дайке Спасская расположены под участком;

- опасные процессы могут быть только в западной части.

Визуальное обследование поверхности показало, что территория выровнена под застройку и любые старые опасные проявления сдвижения горных пород уничтожены. На спланированной поверхности свежие трещины и провалы отсутствуют. По словам местных жителей, рельеф до выравнивания имел в юго- западной части проседание диаметром 2 м и глубиной 0,5 м. При анализе архивных космических фотоснимков за 2001-2020 гг. изменений поверхности выше разрешающей способности снимков, не установлено. Анализ журналов регистрации провалов на территории Березовского золоторудного месторождения выполнен с помощью базы данных провалов [28]. За 1957-2014 гг. в районе участка не зарегистрировано ни одного случая обрушения поверхности или других опасных явлений. С учетом длительного периода после окончания разработки (более 170 лет), малых объемов выработок, отсутствием на поверхности свежих и старых проседаний процесс сдвижения теоретически можно отнести к стадии окончания, что позволяет строительство некоторых зданий.

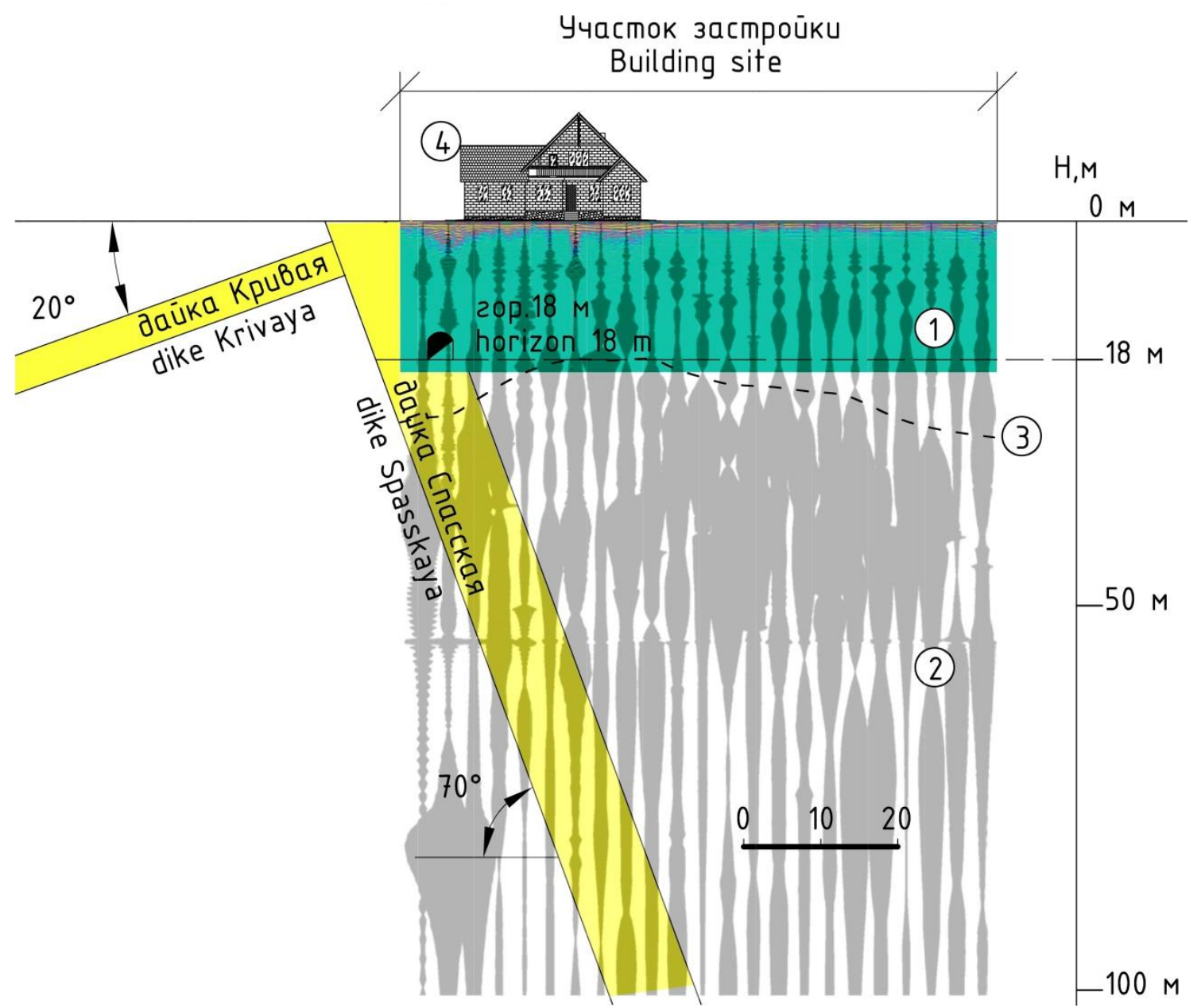

Рис. 4. Двумерная модель залегания подземных горных выработок под участком строительства коттеджа: 1) радарограмма; 2) спектрограмма; 3) граница выветривания; 4) проектное расположение коттеджа

Fig. 4. Two-dimensional model of underground mine workings under the cottage construction site: 1) radarogram; 2) spectrogram; 3) weathering boundary; 4) cottage design location

Для повышения надежности оценки безопасности строительства геофизическими методами обследована структура подработанного горного массива. Методом ССП по всему участку на глубинах 25 м отмечается граница между выветрелыми породами и крепким скальным основанием. В юго-западном углу георадаром выявлена зона глубиной 3 м, заполненная крупно- и мелкообломочным материалом. Индикато- ры, которые могут быть идентифицированы как пустоты или дезинтегрированный массив, не обнаружены обоими методами.

\section{Обсуждение результатов}

В результате исследования горно-геологических условий заброшенной шахты по дайке Спасская и Кривая Березовского месторождения, визуального 
обследования поверхности, геофизических исследований массива горных пород в исследуемых границах, где предполагается строительство коттеджа, пустоты значимых размеров от подземных выработок отсутствуют. Это позволяет рассчитывать на безопасное строительство коттеджа в западной части в соответствии с желанием застройщика.

Под участком могут присутствовать микропустоты объемом до $1 \mathrm{~m}^{3}$ на глубине 18 м. Эти пустоты могут быть расположены только в западной части. На остальной площади подземных горных выработок нет. Интенсивные и опасные деформации грунта исключаются.

Из возможных вредных проявлений от подземной разработки в западной части могут произойти локальные просадки диаметром до 1-2 м и глубиной до 0,5 м. Наиболее вероятно, что такие явления могут быть в полосе шириной 5 м от западной границы участка. Они развиваются чаще всего в весенний и осенний периоды, когда количество атмосферных осадков увеличивается. Периодичность появления просадок составляет одно событие раз в 30-40 лет.

Эти параметры установлены из анализа базы провалов на Березовском месторождении, которая охватывает более 1100 случаев за 57 лет [28]. За это время небольшие проседания под конструкциями зданий проявлялись неоднократно и никогда не причиняли необратимых разрушений конструкций.

\section{Ограничения исследования}

и обобщения его результатов

Предложения по практическому применению

В отношении частоты проявления просадок есть условия, которые могут увеличить их частоту. Это гидрогеологический режим. В настоящее время разработчик месторождения ведет водоотлив с глубины 500 м, и это создает водную депрессию в городе [11] Если в результате полного истощения месторождения откачка воды будет прекращена, то обводнение горных пород в районе заброшенных шахт изменит их устойчивость. Об этом условии застройщик предупрежден.

Снижение частоты проседаний и их последствий необходимо компенсировать геотехническими мерами. Наиболее рациональными с учетом финансового бюджета застройщика станут следующие меры:

1. Визуальный осмотр территории с целью раннего обнаружения проседаний, провалов и т. п. Осмотры необходимо проводить во время весеннего таяния снега (апрель, май) и в дождливый осенний период (сентябрь-ноябрь). Образование луж в местах, где они ранее отсутствовали, является признаком проседания поверхности.

2. Просадки поверхности засыпать скальным грунтом или щебнем с уплотнением. После ликвидации просадки установить вокруг опасной зоны ограждение на один месяц. В период активной стадии исключить доступ к месту деформирования людей и техники, не занятых в ликвидации просадки.

3. В соответствии с прогнозом локальные просадки поверхности диаметром до 1-2 м могут появиться в западной части участка, ширина которой 5 м.
Поэтому расположение капитальных сооружений рекомендуется выполнить с отступлением 6 м от западной границы участка.

Для того чтобы быть в полной уверенности об отсутствии значимых пустот, нужно пробурить несколько скважин. Глубина скважин должна составлять $18 \mathrm{м}$.

Результаты исследования используются на стадии планирования вариантов застройки территории и для выбора проектного расположения строений на территории. Исследование снижает риск аварий и чрезвычайных ситуаций при застройке и эксплуатации территорий в местах залегания подземных горных выработок.

Предложения по направлению будущих исследований

Опыт исследования участка земли над заброшенной шахтой, который расположен на краю опасной территории, дополняет нашу коллекцию строительства в опасных местах. Мы исследовали более $300 \mathrm{Ap}$ подработанных территорий в различных городах Свердловской и Челябинской областей России [6-8, $17,18]$. Безаварийная эксплуатация зданий и сооружений на обследованных площадях подтверждает эффективность исследований. В дальнейших планах исследований мы хотим снизить экспертность некоторых оценок безопасности территорий над заброшенными шахтами и создать оценочный рейтинг, который позволит по важным критериям качественно и стандартизировано подходить к регламентированию строительства в опасных местах.

\section{Заключение}

На основе моделирования и инструментальной диагностики геофизическими методами оценено состояние пород подработанного горного массива, сделан прогноз развития процесса сдвижения и даны рекомендации по использованию подработанного земельного участка. Исследованиями установлено, что над заброшенной шахтой можно построить коттедж без риска необратимых повреждений во время эксплуатации. Земля безопасна для строительства и проживания. Определены геометрические параметры и частота проявлений вредного влияния подземной разработки. Потенциальный ущерб для здания минимален, если его расположить с учетом рекомендаций. Конструктивные мероприятия, направленные на противодействие деформациям от подработки, не требуются. В целом позитивные результаты исследований показывают, что в том месте возможно строительство зданий более высокого уровня ответственности, чем коттедж, и повышают стоимость этого земельного участка.

Авторы благодарят исследователя Алексея Замятина лаборатории предотвращения техногенных катастроф Института горного дела в городе Екатеринбург за выполнение геофизических исследований.

Работа выполнена в рамках Госзадания № 0405-2019-0007. Тема 3 (2019-2021 г2.) «Методические основы районирования территории Российской Федерачии по риску техноприродных катастроф, обусловленных современными геодинамическими движениями земной коры, на опасных $и$ уникальных объектах недропользования». 


\section{СПИСОК ЛИТЕРАТУРЫ}

1. Gankhuyag U., Gregoire F. Managing mining for sustainable development: a sourcebook. - Bangkok: United Nations Development Programme/UNDP and UN Environment, 2018. $116 \mathrm{p}$.

2. Challenges and strategies of abandoned mine rehabilitation in South Africa: the case of asbestos mine rehabilitation / H. Cornelissen, I. Watson, E. Adam, T. Malefetse // Journal of Geochemical Exploration Publisher. - 2019. - V. 205. - 106354 URL: https://Doi.org/10.1016/j.gexplo.2019.106354 (дата обращения 08.01.2021)

3. Post-mining regions in Central Europe. Problems, Potentials, Possibilities / Eds. P. Wirth, B. Černič Mali, W. Fischer. München: Oekom, 2012. -274 p.

4. Leigh Sharpe. Civil engineering \& mining related geohazards - a clients guide to the regulatory process. URL: https://www.emcouncils.gov.uk/write/TCA\%20Permissions\%20Pr ocess.pdf/ (дата обращения 08.01.2021).

5. Otamonga J.-P., Poté J.W. Abandoned mines and artisanal and small-scale mining in Democratic Republic of the Congo (DRC) survey and agenda for future research // Journal of Geochemical Exploration. - 2020. - V. 208. - 106394. URL: https://Doi.org/ 10.1016/j.gexplo.2019.106394 (дата обращения 08.01.2021).

6. Усанов С.В. Подработанные подземными работами территории в г. Березовский и оценка возможности их использования // Горный информационно-аналитический бюллетень. - 2010. № 10. - С. 349-352.

7. Усанова А.В., Усанов С.В. Геомеханическая информационная модель влияния ликвидированного подземного рудника в городе Верхняя Пышма // Маркшейдерия и недропользование. 2014. - № 5. - С. 38-40.

8. Усанов С.В., Усанова А.В. Обоснование мер безопасности при застройке территорий над старыми горными выработками по результатам комплексных исследований // Горный информационно-аналитический бюллетень (научно-технический журнал). - 2020. - № 3-1. - С. 246-254. Available at: https:/giabonline.ru/files/Data/2020/3/246-254.pdf (дата обращения 08.01.2021).

9. Есюнин О. Город на «круге дырявого сыра» // Инженерная защита. - 2015. - № 1 (6). - С. 26-35.

10. Мамаев Ю.А., Ястребов А.А. Комплексная защита подработанной территории калийного рудника в Пермском крае РФ // Инженерная защита. - 2015. - № 3 (8). - С. 26-35.

11. Далатказин Т.Ш., Коновалова Ю.П. Прогноз последствий затопления березовского рудника // Проблемы недропользования. - 2017. - № 3 (14). - С. 60-66.

12. Далатказин Т.Ш., Харисов Т.Ф. Исследование последствий затопления подземного рудника на селитебной территории // Известия Тульского государственного университета. Науки о Земле. - 2019. - № 2. - С. 38-51.

13. Cuenca M.C., J. Hooper A., Hanssen R.F. Surface deformation induced by water influx in the abandoned coal mines in Limburg, The Netherlands observed by satellite radar interferometry // Journal of Applied Geophysics. - 2013. - V. 88. - P. 1-11. URL: https://doi.org/10.1016/j.jappgeo.2012.10.003 (дата обращения 08.01.2021).

14. Хоменко В.П. Суффозия: терминология и феноменология // Опасные для строительства геологические процессы: Сборник материалов Международного семинара, посвященного 70-летию доктора геолого-минералогических наук Виктора Петровича Хоменко. - Москва, 8 июня 2018. - М.: Изд-во МИСИ - МГСУ, 2019. - С. 6-15. URL: https://mgsu.ru/resources/izdatelskaya-deyatelnost/izdaniya/ izdaniya-otkr-dostupa/2019/opasniye-d-stroy-geol-proc-y/006015.pdf (дата обращения 08.01.2021)
15. Казначеев П.А., Камшилин А.Н. Опыт наблюдения за процессами провалообразования в городских условиях и возможные способы их мониторинга // Опасные для строительства геологические процессы: Сборник материалов Международного семинара, посвященного 70-летию доктора геологоминералогических наук Виктора Петровича Хоменко. Москва, 8 июня 2018. - М.: Изд-во МИСИ - МГСУ, 2019. C. 30-32. URL: https://ifo.mgsu.ru/resources/izdatelskayadeyatelnost/izdaniya/izdaniya-otkr-dostupa/2019/opasniye-d-stroygeol-proc-y/030-032.pdf (дата обращения 08.01.2021).

16. Ярг Л.А. Методы инженерно-геологических исследований процесса и кор выветривания. - М.: Недра, 1991. - 139 с.

17. Усанов С.В., Усанова А.В. Мониторинг сдвижения поверхности при ликвидации и затоплении горных выработок Лебяжинского месторождения // Горный журнал. - 2017. - № 1. C. 18-22. URL: http://www.rudmet.ru/journal/1593/article/27341/ (дата обращения 08.01.2021).

18. Усанов С.В. Геодинамические движения горного массива при техногенном воздействии крупного горно-обогатительного комбината // Горный информационно-аналитический бюллетень (научно-технический журнал). - 2011. - № S11. - С. 248-255.

19. Березовское золоторудное месторождение (история и минералогия): научное издание / В.Г. Альбрехт, А.С. Баталин, А.А. Баталина, Ю.В. Ерохин, Д.А. Клейменов. - Екатеринбург: Уральский рабочий, 2005. - $200 \mathrm{c}$.

20. Gennaro G.M., Abdolreza O. Building above underground coal mines // Structure magazine. - 2020. URL: https://www. structuremag.org/?p=15768 (дата обращения 10.01.2021).

21. Cole K. Building over abandoned shallow mines. Paper 1: Considerations of risk and reliability // International Journal of Rock Mechanics and Mining Sciences \& Geomechanics Abstracts. - 1993. - V. 30. - Iss. 4. - P. A266. URL: https://doi.org/10.1016/0148-9062(93)92197-X (дата обращения 08.01.2021).

22. BestMaps - спутниковые фотографии и карты всего мира онлайн. URL: https://bestmaps.ru/map/osm/opentopomap/ 6/56.758/61.844 (дата обращения 08.01.2021).

23. Инженерно-геофизические исследования в условиях подработанных территорий / В.П. Колесников, А.М. Пригара, А.В. Татаркин, А.А. Филимончиков // Инженерные изыскания. 2012. - № 9. - C. 69-77.

24. Замятин А.Л. Геофизические исследования на подработанных территориях // Горный информационно-аналитический бюллетень. - 2009. - № 2 - C. 88-93.

25. Luo T.X.H., Lai W.W.L. GPR pattern recognition of shallow subsurface air voids // Tunnelling and Underground Space Technology. - 2020. - V. 99. - 103355. URL: https://doi.org/ 10.1016/j.tust.2020.103355 (дата обращения 08.01.2021).

26. Detecting, locating, and characterizing voids in disaster rubble for search and rescue / DaHu, Shuai Li, Junjie Chen, Vineet R. Kamat // Advanced Engineering Informatics. - 2019. - V. 42. - 100974. URL: https://doi.org/10.1016/j.aei.2019.100974 (дата обращения 08.01.2021)

27. Kotyrba A., Kortas Ł. Sinkhole hazard assessment in the area of abandoned mining shaft basing on microgravity survey and modelling - case study from the Upper Silesia Coal Basin in Poland // Journal of Applied Geophysics. - 2016. - V. 130. P. 62-70. URL: https://Doi.org/10.1016/j.jappgeo.2016.04.007 (дата обращения 08.01.2021).

28. Ведерников А.С., Зуев П.И. Районирование подработанных территорий города Березовский // Горный информационноаналитический бюллетень (научно-технический журнал). 2020. - № 3-1. - C. 37-45. URL: https://giab-online.ru/ files/Data/2020/3/37-45.pdf (дата обращения 08.01.2021)

Поступила 23.06.2021 2.

\section{Информация об авторах}

Усанов C.B., кандидат технических наук, заведующий лабораторией сдвижения горных пород, Институт горного дела Уральского отделения Российской академии наук.

Усанова A.B., научный сотрудник лаборатории геомеханики подземных сооружений, Институт горного дела Уральского отделения Российской академии наук. 
UDC 622.1

\title{
INVESTIGATION OF GROUND COLLAPSES OVER A SHALLOW ABANDONED MINE TO DETERMINE THE GEOTECHNICAL CONDITIONS OF INDIVIDUAL CONSTRUCTION
}

\author{
Sergey V. Usanov ${ }^{1}$, \\ usv@igduran.ru
}

\author{
Anna V. Usanova ${ }^{1}$, \\ anne.usanova@gmail.com \\ 1 Institute of Mining of Ural branch of RAS, \\ 58, Mamin-Sibiryak street, Yekaterinburg, 620075, Russia.
}

\begin{abstract}
The relevance of the study is caused by the need to construct buildings and structures over old abandoned mines. Construction is associated with the danger of failure of the earth's surface and the destruction of buildings. This problem is widespread all over the world.

The aim of the research is to determine the risk of building a small plot of land located above an old gold mine and the parameters of likely hazardous processes; to predict potential damage.

Methods: analysis of archival geological documents abandoned mines, reconstruction and two-dimensional modeling of mine workings under the studied area, on-site visual examination of the surface analysis of optical satellite imagery database analysis of the collapse surface geophysical sensing of the mountain massif with the surface.

Results. Using two-dimensional modeling, it was found that only one of two granitoid dikes developed within the boundaries of the study, is dangerous, since the other, according to geological conditions, is the main body lying outside the study. This facilitates the conditions for construction. Dangerous processes from the drift and orta dike, which falls on the site, can only be in the westernmost part with a width of $5 \mathrm{~m}$. It is established that since 1957, no surface failures have been observed in this place, and the dangerous phenomena registered in the vicinity are the subsidence of the soil with a diameter of 1-2 $\mathrm{m}$ and a depth of 0,5 $\mathrm{m}$. In the southwestern corner of the site above ort, a 3-meter-deep zone filled with coarse and fine-grained material was detected, which is most likely a trace of its collapse. Indicators that can be identified as voids or a disintegrated array are not detected by two methods.

Conclusions. The authors have made forecast of the parameters of an old mine harmful effect on stability of the surface. The research established that a cottage can be built on this site above an abandoned mine without the risk of permanent damage during operation. The land is safe for construction and living. The geometric parameters of the probable harmful effect of underground mining and the frequency of manifestations are determined. Geotechnical measures to minimize the possible harmful effects of an abandoned mine are proposed.
\end{abstract}

\section{Key words:}

Abandoned mine, old mine workings, ground collapse, subsidence, construction, safety, forecast and assessment, geotechnical measures, building placement conditions.

The authors appreciate Aleksey Zamyatin, the researcher of the laboratory of preventing human-made disasters at Mining Institute, Yekaterinburg, for geophysical research.

The research was carried out within the State task no. 0405-2019-0007. Topic 3 (2019-2021) «Methodological bases of zoning the territory of the Russian Federation by the risk of human-made disasters, caused by modern geodynamic movements of earth crust, at dangerous and unique objects of subsoil management».

\section{REFERENCES}

1. Gankhuyag U., Gregoire F. Managing mining for sustainable development: a sourcebook. Bangkok, United Nations Development Programme, UNDP and UN Environment, 2018. 116 p.

2. Cornelissen H., Watson I., Adam E., Malefetse T. Challenges and strategies of abandoned mine rehabilitation in South Africa: the case of asbestos mine rehabilitation. Journal of Geochemical Exploration Publisher, 2019, vol. 205, 106354. Available at: https://Doi.org/10.1016/j.gexplo.2019.106354 (accessed 8 January 2021)

3. Post-Mining Regions in Central Europe. Problems, Potentials, Possibilities. Eds. P. Wirth, B. Černič Mali, W. Fischer. München, Oekom, 2012. $274 \mathrm{p}$.

4. Leigh Sharpe. Civil engineering \& mining related geohazards - a clients guide to the regulatory process. Available at: https://www.emcouncils.gov.uk/write/TCA\%20Permissions\%20Pr ocess.pdf/ (accessed 8 January 2021)

5. Otamonga J.-P., Poté J.W. Abandoned mines and artisanal and small-scale mining in Democratic Republic of the Congo (DRC). Survey and agenda for future research. Journal of Geochemical Exploration, 2020, vol. 208, 106394. Available at: https:// Doi.org/10.1016/j.gexplo.2019.106394 (accessed 8 January 2021).
6. Usanov S.V. Podrabotannye podzemnymi rabotami territorii v g. Berezovskiy i otsenka vozmozhnosti ikh ispolzovaniya [The territories underworked by underground works in Berezovsky and the assessment of the possibility of their use]. Gorny informatsionnoanaliticheskiy bjulleten, 2010, no. 10. pp. 349-352.

7. Usanova A.V., Usanov S.V. Geomechanical information model of abandoned underground mine influence in Verkhnyaya Pyshma. Surveying and Subsurface Use, 2014, no. 5, pp. 38-40. In Rus.

8. Usanov S.V., Usanova A.V. Justification of safety measures at the construction of territories over old underground mining by the results of complex researches. Mining informational and analytical bulletin (scientific and technical journal). 2020, no. 3-1. pp. 246-254. Available at: https: https://giab-online.ru/files/Data/2020/3/246-254.pdf (accessed 8 January 2021).

9. Esyunin O. Gorod na «kruge dyryavogo syra» [City on the «circle of leaky cheese»]. Inzhenernaya zashchita, 2015, no. 1 (6), pp. 26-35.

10. Mamaev Yu.A., Yastrebov A.A. Kompleksnaya zashchita podrabotannoy territorii kaliynogo rudnika v Permskom krae RF [Comprehensive protection of the under-developed territory of a potash mine in the Perm Region of the Russian Federation]. Inzhenernaya zashchita, 2015, no. 3 (8), pp. 26-35.

11. Dalatkazin T.Sh., Konovalova Ju.P. Consequences forecast of the Berezovsky mine flooding. Problems of Subsurface Use, 2017, no. 3 (14), pp. 60-66. In Rus. 
12. Dalatkazin T.Sh., Harisov T.F. Research of consequences of flooding of the underground mine in the residential territory. Izvestiya Tula State University. Earth Sciences, 2019, no. 2, pp. 38-51. In Rus.

13. Cuenca M.C., Hooper J.A., Hanssen R.F. Surface deformation induced by water influx in the abandoned coal mines in Limburg, The Netherlands observed by satellite radar interferometry. Journal of Applied Geophysics, 2013, vol. 88, pp. 1-11. Available at: https://doi.org/10.1016/j.jappgeo.2012.10.003 (accessed 8 January 2021).

14. Khomenko V.P. Suffoziya: terminologiya i fenomenologiya [Suffusion: terminology and phenomenology]. Opasnye dlya stroitelstva geologicheskie protsessy: Sbornik materialov Mezhdunarodnogo seminara, posvyashchennogo 70-letiyu doktora geologo-mineralogicheskikh nauk Viktora Petrovicha Khomenko [Geological processes that are dangerous for construction: collection of materials of the International Seminar dedicated to the $70^{\text {th }}$ anniversary of Doctor of Geological and Mineralogical Sciences Viktor Petrovich Khomenko]. Moscow, MISI - MGSU Publ., 2019. pp. 6-15. Available at: https://mgsu.ru/resources/ izdatelskaya-deyatelnost/izdaniya/izdaniya-otkr-dostupa/2019/ opasniye-d-stroy-geol-proc-y/006-015.pdf (accessed 8 January 2021).

15. Kaznacheev P.A., Kamshilin A.N. Opyt nablyudenija za protsessami provaloobrazovaniya $\mathrm{v}$ gorodskikh usloviyakh i vozmozhnye sposoby ikh monitoringa [Experience of observing the processes of sinkhole formation in urban conditions and possible ways of monitoring them]. Opasnye dlya stroitelstva geologicheskie protsessy: Sbornik materialov Mezhdunarodnogo seminara, posvyashchennogo 70-letiyu doktora geologo-mineralogicheskikh nauk Viktora Petrovicha Khomenko [Geological processes that are dangerous for construction: collection of materials of the International Seminar dedicated to the $70^{\text {th }}$ anniversary of Doctor of Geological and Mineralogical Sciences Viktor Petrovich Khomenko]. Moscow, MISI - MGSU Publ., 2019. pp. 30-32. Available at: https://ifo.mgsu.ru/resources/izdatelskayadeyatelnost/izdaniya/izdaniya-otkr-dostupa/2019/opasniye-d-stroygeol-proc-y/030-032.pdf (accessed 8 January 2021).

16. Metody inzhenerno-geologicheskikh issledovaniy protsessa $i \mathrm{kor}$ vyvetrivaniya [Methods of engineering and geological studies of the weathering process and crust]. Jarg L.A. Moscow, Nedra Publ., $1991.139 \mathrm{p}$.

17. Usanov S.V., Usanova A.V. Monitoring sdvizheniya poverkhnosti pri likvidatsii i zatoplenii gornykh vyrabotok Lebyazhinskogo mestorozhdeniya [Monitoring of surface movement during liquidation and flooding of mine workings of the Lebyazhinsky field]. Gorny zhurnal, 2017, no. 1, pp. 18-22. Available at: http://www.rudmet.ru/journal/1593/article/27341/ (accessed 8 January 2021).
18. Usanov S.V. Geodynamic movements of rock massif at technogenic influence of the large mountain enterprise. Mining informational and analytical bulletin (scientific and technical journal), 2011, no. S11, pp. 248-255. In Rus.

19. Albreht V.G., Batalin A.S., Batalina A.A., Erokhin Yu.V., Kleymenov D.A. Berezovskoe zolotorudnoe mestorozhdenie (istoriya $i$ mineralogiya): nauchnoe izdanie [Berezovskoe gold deposit (history and mineralogy): scientific publication]. Ekaterinburg, Uralskiy rabochiy Pub., 2005. 200 p.

20. Gennaro G.M., Abdolreza O. Building above underground coal mines. Structure magazine, 2020. Available at: https://www. structuremag.org/?p=15768 (accessed 8 January 2021).

21. Cole K. Building over abandoned shallow mines. Paper 1: Considerations of risk and reliability. International Journal of Rock Mechanics and Mining Sciences \& Geomechanics Abstracts, 1993, vol. 30, Iss. 4. pp. A266. Available at: https://doi.org/10.1016/ 0148-9062(93)92197-X (accessed 8 January 2021).

22. BestMaps - satellite photos and maps of the whole world online. Available at: https://bestmaps.ru/map/osm/opentopomap/6/56.758/ 61.844 (accessed 8 January 2021)

23. Kolesnikov V.P., A.M. Prigara, A.V. Tatarkin, A.A. Filimonchikov. Engineering-geophysical investigations under conditionsof undermined areas. Engineering surveys, 2012, no. 9, pp. 69-77. In Rus.

24. Zamyatin A.L. Geofizicheskie issledovaniya na podrabotannykh territoriyakh [Geophysical research in sub-developed areas]. Gorny informatsionno-analiticheskiy byulleten, 2009, no. 2, pp. 88-93.

25. Luo T.X.H., Lai W.W.L. GPR pattern recognition of shallow subsurface air voids. Tunnelling and Underground Space Technology, 2020, vol. 99, 103355. Available at: https://doi.org/10.1016/ j.tust.2020.103355 (accessed 8 January 2021).

26. DaHu, Shuai Li, Junjie Chen, Vineet R. Kamat. Detecting, locating, and characterizing voids in disaster rubble for search and rescue. Advanced Engineering Informatics, 2019, vol. 42, 100974. Available at: https://doi.org/10.1016/j.aei.2019.100974 (accessed 8 January 2021).

27. Kotyrba A., Kortas Ł. Sinkhole hazard assessment in the area of abandoned mining shaft basing on microgravity survey and modelling - case study from the Upper Silesia Coal Basin in Poland. Journal of Applied Geophysics, 2016, vol. 130, pp. 62-70. Available at: https://Doi.org/10.1016/j.jappgeo.2016.04.007 (accessed 8 January 2021).

28. Vedernikov A.S., Zuev P.I. Zoning of undermined urban territories in the area of the Berezovsky town. Mining informational and analytical bulletin (scientific and technical journal, 2020, no. 3-1, pp. 37-45. In Rus. Available at: https://giab-online.ru/files/Data/ 2020/3/37-45.pdf (accessed 8 January 2021).

Received 23 June 2021.

\section{Information about the authors}

Sergey V. Usanov, Cand. Sc., laboratory chief, Institute of Mining of Ural branch of RAS.

Anna V. Usanova, researcher, Institute of Mining of Ural branch of RAS. 